\title{
Incidence, Identification, and Mycoparasitic Activity of Clonostachys epichloë, a Hyperparasite of the Fungal Endophyte Epichloë typhina
}

\author{
Karolina Górzyńska ${ }^{\dagger}$ and Magdalena Ślachetka, Department of Plant Taxonomy, Adam Mickiewicz University in Poznań, Poland; \\ Przemysław Ryszka and Katarzyna Turnau, Institute of Environmental Sciences, Jagiellonian University in Kraków, Poland; Bartosz J. \\ Płachno, Department of Plant Cytology and Embryology, Institute of Botany, Jagiellonian University in Kraków, Poland; and Marlena \\ Lembicz, Department of Plant Taxonomy, Adam Mickiewicz University in Poznań, Poland
}

\begin{abstract}
Fungi of the genus Epichlö (Clavicipitaceae, Ascomycota) cause choke disease in many grass species. The disease manifests itself as fungal stromata that form around developing inflorescences, thereby suppressing their maturation. Economic losses in agricultural production due to choke have long been known in the U.S.A. and France, but attempts to control choke disease have not been successful. The interaction between Epichloë typhina (Pers.) Tul. \& C. Tul. and its naturally occurring fungal hyperparasite, Clonostachys epichloë (Speg.) Schroers (sexual morph Bionectria epichlö̈) was investigated in populations of the grass $P$ uccinellia distans (L.) Parl. Fungal hyperparasites occur widely in nature, and

many are successfully used commercially as biological control agents against plant pathogenic fungi. Microscopy of Epichloë stromata infected with $C$. epichloë revealed a lack of asci with ascospores in perithecia and damage to mycelia at sites colonized by C. epichloë. The ability of C. epichloë to colonize E. typhina was confirmed via two in vitro experiments. The percent inhibition of growth of E. typhina strains by C. epichloë varied from 18.40 to $46.50 \%$, and the mycoparasite colonized up to $100 \%$ of Epichloë mycelia in a precolonization experiment. We discuss the possibility of using C. epichloë to control choke disease caused by E. typhina in grass populations.
\end{abstract}

Choke disease is a condition of grass in which the development of inflorescences is suppressed by mycelial stromata (Western and Cavett 1959). This disease is caused by fungi of the genus Epichlö (Clavicipitaceae, Ascomycota), which form symbiotic associations with cool-season grasses. During the vegetative phase of the host grass, fungal hyphae grow in plant tissues without causing visible signs of infection (Schardl 1996). In spring, some Epichloë species may form external stromata that form around the developing plant inflorescences, thereby suppressing their maturation and seed production. Fungal mating takes place on stromata, upon which ascospores capable of infecting new grass plants are produced (Chung and Schardl 1997). Thirty-five Epichloë species have been described, and 11 of them produce stromata (Leuchtmann et al. 2014).

Economic losses in agricultural production due to Epichloë have been recognized. For example, fungal infection was estimated to cause serious losses (more than $\$ 820,000$ per year) in orchardgrass (Dactylis glomerata) yields in the Willamette Valley (Oregon, U.S.A.), where $90 \%$ of fields were infected with E. typhina (Pfender and Alderman 2006). The incidence of choke commonly reaches $30 \%$ in orchardgrass fields in France by the fourth year of seed production, making the stand unprofitable (Raynal 1991). Direct losses due to choke disease were estimated at more than $\$ 100,000$ in the Czech Republic in 2008 (Cagaš and Macháč 2012). Previous attempts to control the spread of choke disease have not yielded the desired results. Chemical fungicides such as propiconazole and azoxystrobin

${ }^{\dagger}$ Corresponding author: K. Górzyńska; E-mail: karjan@amu.edu.pl

Funding: This work was funded by National Science Centre, grant number UMO-2014/13/D/NZ8/02420 (to K. Górzyńska). Part of this research (i.e. anatomical part) was supported financially by the Ministry of Science and Higher Education of Poland as part of the statutory activities of the Department of Plant Cytology and Embryology (B. J. Płachno), Institute of Botany at the Jagiellonian University in Kraków. The publication costs of this article were supported by the KNOW RNA Research Centre in Poznań (No. 01/ KNOW2/2014).

Accepted for publication 11 April 2018.

(c) 2018 The American Phytopathological Society
(Pfender and Alderman 2003) and the copper fungicides Kocide 3000 and Copper-Count N (Alderman et al. 2008) have failed to control the disease. The only method that achieves satisfactory results is the frequent rotation of crops, resulting in the rapid liquidation of unprofitable crops and the establishment of new cultivated areas in other locations, which can be costly (Pfender and Alderman 2003). An effective but high-cost approach is to burn plant residues; during this process, the above-ground parts of plants are destroyed along with endophytes, reducing the level of disease the following year. Unfortunately, this type of action, apart from the obvious devastation to the ecosystem, is difficult to control over larger cultivated areas.

It has recently been suggested that other fungi found on Epichlö stromata are potentially effective biocontrol agents against choke disease. Alderman et al. (2010) found a fungal hyperparasite, Dicyma pulvinata, on E. typhina stromata in orchardgrass fields in the United States. Infected stromata had fewer perithecia and were stunted and pale gray, in contrast to the orange-colored noninfected stromata with mature perithecia. These results suggest that naturally occurring fungi on Epichloë stromata may be useful biocontrol agents in reducing dissemination of ascospores. Although further studies of $D$. pulvinata against choke disease have been abandoned, the application of fungal hyperparasites seem promising because some of them have already been commercially used, e.g., a biofungicide with active Trichoderma harzianum spores sold under the trade name Trichodex WP (Makhteshim Chemical Works, LTD) controls Botrytis cinerea (gray mold) in greenhouse crops and vineyards, Sclerotinia sclerotiorum (white mold) in various greenhouse and field crops, Cladosporium fulvum (leaf mold) in tomato, and the powdery mildew Sphaerotheca fusca in cucurbits (Elad 2000). Mycoparasitism is widespread in nature (Jeffries 1995; Jeffries and Young 1994), and has been intensely studied as a potential biocontrol measure in fungal diseases. For instance, the mycoparasite Sphaerellopsis filum decreases the winter survival of Puccinia graminis in perennial ryegrass (Gordon and Pfender 2012), Clonostachys rosea has potential as a biocontrol agent for the control of alfalfa blossom blight caused by B. cinerea (Li et al. 2004), while Sphaerodes retispora may play a similar role against watermelon wilt caused by Fusarium oxysporum (Harveson et al. 2002).

The number of grass species reported to be infected with Epichlö fungi in Poland continues to increase (Lembicz et al. 2010; Żurek 
et al. 2012). In some populations of Puccinellia distans, a grass species that serves as a model for fungus-plant interaction studies, as many as $90 \%$ of individuals were infected with Epichloë typhina (Lembicz et al. 2011; Lembicz and Olejniczak 2009). We observed dark green spots on the stromata of E. typhina infecting the grass species $P$. distans in 2010. Preliminary analyses showed that these spots were caused by a hyperparasite. The present study is aimed at (i) identification of the hyperparasite, (ii) determine its incidence in the E. typhina-P. distans association, (iii) assessing the effects of its presence on the sexual reproduction of E. typhina, and (iv) assessing its mycoparasitic ability in vitro.

\section{Materials and Methods}

Study system. The fungus E. typhina (Pers.) Tul. \& C. Tul. grows endophytically in tissues of aerial parts of host plants, forming systemic and asymptomatic associations (Schardl 1996). Fungi of this genus are transmitted vertically in seeds from plants to their offspring. The endophytic stage of Epichloë may increase the growth, reproduction, and antiherbivore protection of their hosts (Brem and Leuchtmann 2001; Gundel et al. 2006; Novas et al. 2003). The latter is possible thanks to the production of antiherbivore alkaloids produced by the fungus (e.g., Schardl et al. 2007). However, positive fungal effects depend on many factors such as the particular host and endophyte genotype combinations, environmental conditions, and host age (Hesse et al. 2005; Malinowski et al. 2000; Olejniczak and Lembicz 2007). Additionally, the mycotoxins produced by these fungi cause many adverse symptoms in farm animals that feed on the infected grasses (Guerre 2016; Hoveland 1993) and in other herbivores living in grassland ecosystems (Conover 2003; Czarnoleski et al. 2012; Meister et al. 2006). In spring, some Epichloë species

Table 1. Origin of Epichloë typhina and fungi found on its stromata, sampling sites, and GenBank accession nos. of sequences obtained from the isolates corresponding to each studied locality

\begin{tabular}{|c|c|c|c|c|c|c|}
\hline Site & Habitat & Location & Fungus & Strain symbol & GenBank accession no. & Species identified \\
\hline \multirow[t]{2}{*}{ Giebnia } & \multirow{2}{*}{$\begin{array}{l}\text { Grassland in the vicinity } \\
\text { of the soda production plant }\end{array}$} & $52^{\circ} 46.544^{\prime} \mathrm{N}$ & Epichloë typhina & EpiG & MG280831 & Epichloë typhina \\
\hline & & $18^{\circ} 06.190^{\prime} \mathrm{E}$ & hyperparasite & CloG & KX812527 & Clonostachys epichloè \\
\hline \multirow[t]{2}{*}{ Janikowo } & \multirow[t]{2}{*}{ Grassland on former farmland } & $52^{\circ} 46.384^{\prime} \mathrm{N}$ & Epichloë typhina & EpiJ & MG280830 & Epichloë typhina \\
\hline & & $18^{\circ} 08.032^{\prime} \mathrm{E}$ & hyperparasite & CloJ & KT948055 & Clonostachys epichloè \\
\hline \multirow[t]{2}{*}{ Pakość } & \multirow[t]{2}{*}{ Pasture with extensive grazing } & $52^{\circ} 47.293^{\prime} \mathrm{N}$ & Epichloë typhina & EpiP & MG280832 & Epichloë typhina \\
\hline & & $18^{\circ} 06.721^{\prime} \mathrm{E}$ & hyperparasite & CloP & KX812528 & Clonostachys epichloè \\
\hline
\end{tabular}
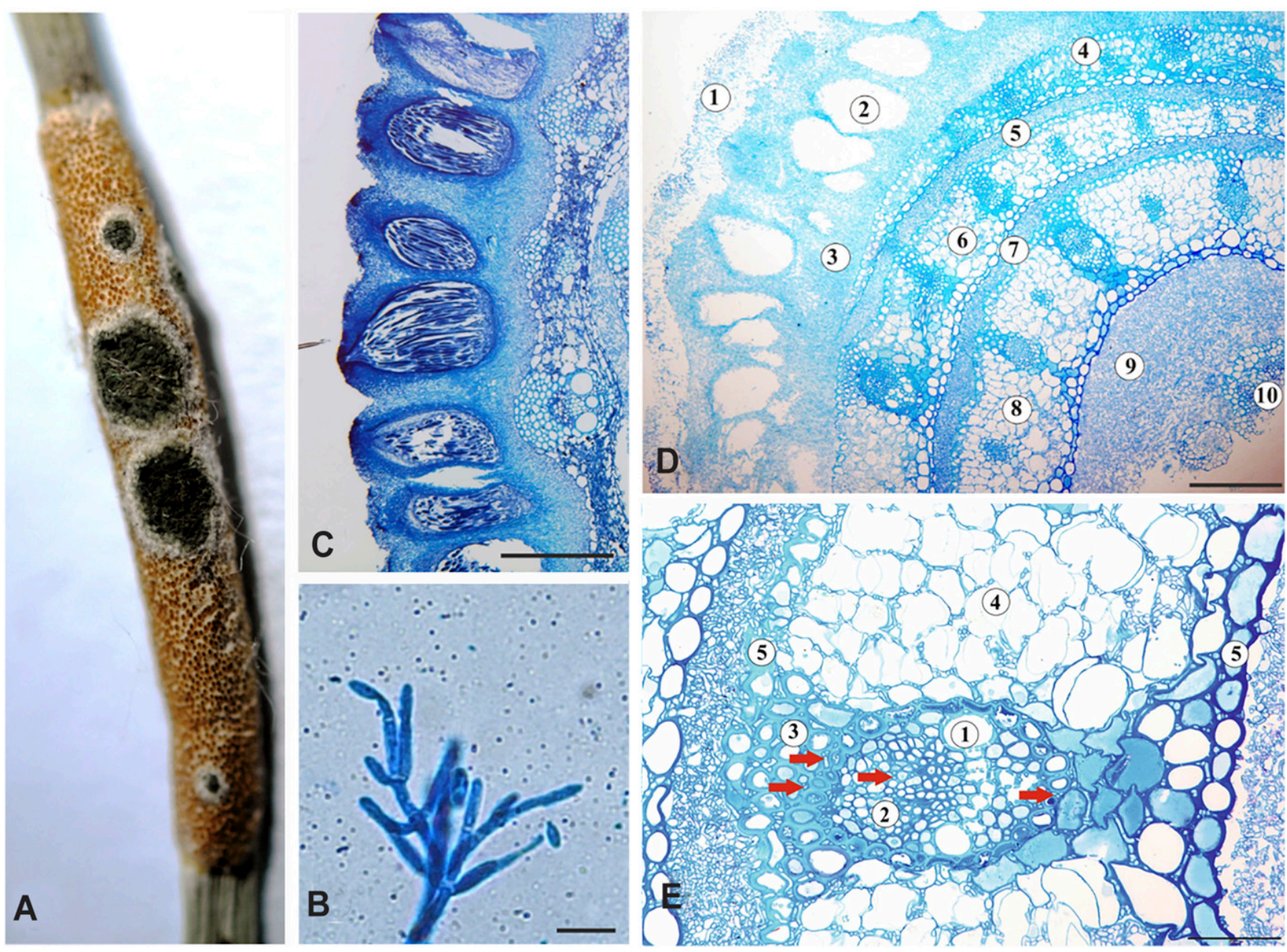

Fig. 1. Clonostachys epichloë infecting the stromata of Epichloë typhina on the grass species Puccinellia distans. A, green conidial masses produced by C. epichloë on the orange stroma of $E$. typhina. B, divergently branched conidiophores (from cultures on PDA), bar $=10 \mu \mathrm{m}$. C, transverse section through an uninfected part of $E$. typhina stroma showing perithecia with asci, bar $=200 \mu \mathrm{m}$. D, transverse section through an infected part of stroma directly beneath the mycoparasite: $1, \mathrm{C}$. epichloë; 2, an empty perithecium, where asci development appeared to be suppressed; 3 , hyphae on the plant surface; 4,6 , and 8 , leaf sheathes; 5 and 7 , layers of hyphae; 9 , hyphae inside the stroma and surrounding the stem; and 10, stem (inflorescence). Bar $=200 \mu \mathrm{m} . \mathbf{C}$ and $\mathbf{D}$ show different parts of the same stroma. $\mathbf{E}$, part of a transverse section through a leaf trapped within the stroma; the red arrow indicates a sample of hyphae between the cells: 1, xylem (vessel); 2, phloem; 3, sclerenchyma; 4, mesophyll; and 5, epidermis. Bar $=50 \mu \mathrm{m}$. 
enter a sexual life cycle and produce external white stromata fully covered with conidia. Stromata enclose grass shoots, preventing their further development and consequently restricting the flowering and seed production of infected plants (Chung and Schardl 1997). This condition is known as 'choke disease' (Western and Cavett 1959). This fungus is heterothallic, and its sexual reproduction depends on the transport of conidia (spermatia) to an individual of the opposite mating type. The usual vectors are Botanophila flies (Bultman et al. 1998), which are specifically attracted by volatile compounds of the fungus (Steinebrunner et al. 2008c). Following mating, perithecia containing asci with ascospores develop, and stromata turn from white to orange. Mature ascospores are ejected from perithecia and initiate new infections of neighboring plants (horizontal transmission) (Chung and Schardl 1997).

$P$. distans (L.) Parl. is a perennial Euro-Siberian halophyte occurring on marine and inland salines (Hughes and Hallidays 1980). The first symptoms of choke disease caused by E. typhina were observed in 1992, in a single population of $P$. distans in central Poland (Lembicz 1996). The frequency of infected individuals in this population increased from 7.5\% in 1992 to $91.2 \%$ in 2003 (Lembicz 1996; Lembicz et al. 2011). E. typhina has been recorded in five populations of $P$. distans, with all growing in anthropogenic habitats (Lembicz and Olejniczak 2009). The association between E. typhina and $P$. distans has already been investigated in several studies (Czarnoleski et al. 2013; Górzyńska et al. 2011, 2017; Lembicz et al. 2011, 2013; Olejniczak and Lembicz 2007); we reported a previously unrecorded hyperparasite appearing as dark green spots on E. typhina stromata in 2010 (M. Lembicz and K. Górzyńska, annual report, unpublished).

Identification and incidence. The identification and distribution of the hyperparasitic fungus were studied at three localities of $P$. distans-E. typhina associations in the vicinity of Inowrocław, Poland (Table 1). To evaluate the distribution of the hyperparasite, we collected 130 stromata of E. typhina at each locality at the end of June. At each of three localities, a plot of $130 \mathrm{~m}^{2}$ was delimited and subdivided into subplots of $1 \mathrm{~m}^{2}$. One stroma from an infected $P$. distans individual was collected within each subplot. Stomata were analyzed for the presence of the hyperparasite, and the proportion of stroma covered by its mycelium was evaluated visually $(<25 \%$ of the area, 25 to $50 \%$, or $>50 \%$ ).

The stromata of E. typhina gathered at each site were analyzed using a dissecting microscope (Olympus SZ61). Isolates of the hyperparasite were collected from stromata by touching a drop of sterile water to the sporulating surface and spreading the conidia that adhered to the drop over the surface of potato dextrose agar (PDA) plates with a glass rod. Mycelia were grown in an incubator at $25^{\circ} \mathrm{C}$. The fungus was identified based on its microscopic characteristics, which were compared with information provided by Schroers (2001) and Kirschner (2006). These colonies were also used for molecular identification and dual-culture experiments.

Five isolates from the stromata of each of the three different origins (for a total of 15; Table 1) were additionally identified using molecular methods. To isolate DNA, we ground mycelia of the hyperparasitic fungus separately in liquid nitrogen in $1.5 \mathrm{ml}$ microcentrifuge tubes. DNA was isolated using a DNeasy Plant Mini Kit (Qiagen, Germany) according to the manufacturer's protocol and then stored at $-20^{\circ} \mathrm{C}$. A pair of primers, ITS1F (Gardes and Bruns 1993) and ITS4 (White et al. 1990), was employed to amplify the ribosomal cassette, which consisted of SSU (partial), ITS1, 5.8S, ITS2, and LSU (partial) rDNA. PCR was performed in a total volume of $25 \mu \mathrm{l}$ containing $12.5 \mu \mathrm{l}$ of $2 \times \mathrm{PCR}$ MasterMix (Fermentas, Lithuania), $1 \mu$ l of each primer $(10 \mathrm{pmol} / \mu \mathrm{l}), 5.5 \mu \mathrm{l}$ of nucleasefree water, and $5 \mu \mathrm{l}$ of DNA template. The amplification cycling conditions were as follows: initial denaturation $\left(94^{\circ} \mathrm{C}, 4 \mathrm{~min}\right) ; 35$ cycles of denaturation $\left(94^{\circ} \mathrm{C}, 30 \mathrm{~s}\right)$, primer annealing $\left(55^{\circ} \mathrm{C}, 30 \mathrm{~s}\right)$, and product extension $\left(72^{\circ} \mathrm{C}, 30 \mathrm{~s}\right)$; and a final extension $\left(72^{\circ} \mathrm{C}, 5 \mathrm{~min}\right)$. The PCR products were then cycle-sequenced with an ABI BigDye Terminator ver. 3.1 (Applied Biosystems, U.S.A.). The analyses were conducted at the Institute of Environmental Sciences, Jagiellonian University (IES UJ), Cracow, Poland, and in the Plant Taxonomy Department, A. Mickiewicz University, Poznan, Poland. The obtained sequences were submitted to GenBank (Table 1).

Obtained sequences and sequences of best BLAST matches $(99 \%$ for sequences from Janikowo and Pakość and 100\% for those from Giebnia) along with other sequences available in GenBank were selected for further analysis. Sequences were aligned using MAFFT

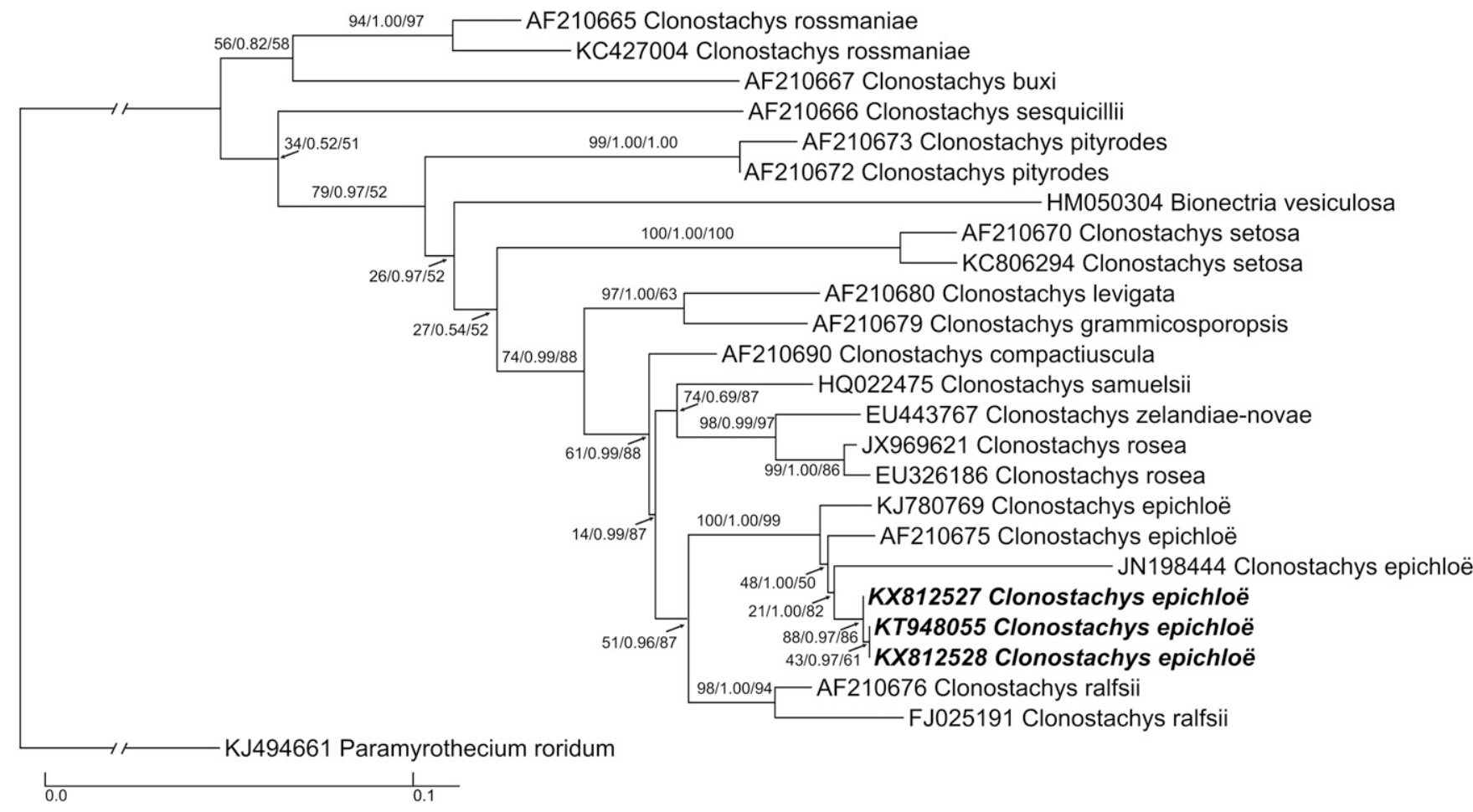

Fig. 2. Phylogenetic relationships among obtained sequences. A maximum likelihood tree based on the internal transcribed spacer (ITS) region sequences is shown. Values at the nodes indicate the tree topology support: maximum likelihood bootstrap values (5,000 replicates) are followed by Bayesian posterior probabilities $(7,000,000$ generations, two runs and four chains) and neighbor-joining bootstrap values (50,000 replicates). Sequences obtained during this study are given in bold italics. 
(Katoh et al. 2002; Katoh and Standley 2013). The phylogenetic relationships between sequences were inferred using the maximum likelihood method (PhyML - Guindon et al. 2010). Bayesian posterior probabilities of the tree topology were calculated using MrBayes ver. 3.1.2 (Ronquist and Huelsenbeck 2003). Analysis with the neighbor-joining method as implemented in PAUP* ver. 4.0 (Swofford 1998) was also included. All analyses were performed with the evolutionary model set to the generalized time-reversible (GTR) model with gamma-distributed rate variation across sites and a proportion of invariable sites.

Effects on the sexual reproduction of E. typhina. The hyperparasitic fungus in the structures of Epichloë stromata. Three infected plants from each site were collected, and from each plant, four stromata were chosen for sectioning (36 altogether). The samples were prepared as described previously (Płachno and Świątek 2009, 2010). Briefly, the material was fixed in $2.5 \%$ formaldehyde and $2.5 \%$ glutaraldehyde in $0.05 \mathrm{M}$ cacodylate buffer ( $\mathrm{pH} 7.0)$ for 2 days. The material was then postfixed in $1 \% \mathrm{OsO}_{4}$ in cacodylate buffer for $24 \mathrm{~h}$ at $\sim 4^{\circ} \mathrm{C}$, rinsed in the same buffer, treated with $1 \%$ uranyl acetate in distilled water for $1 \mathrm{~h}$, dehydrated with acetone, and embedded in Epoxy Embedding Medium (Fluka). Semithin sections ( $0.8 \mu \mathrm{m}$ thick) were cut using a Leica Ultracut UCT ultramicrotome (Leica Microsystems, Wetzlar, Germany) and stained with methylene blue and examined under an Olympus BX60 microscope. Some fixed material was hand-sectioned and examined under an Olympus BX60 microscope with a DP12 digital camera (Olympus, Tokyo, Japan) and AnalySIS 3.2 software (Olympus Soft Imaging Solutions, Münster, Germany). For each infected stroma, both infected and noninfected parts were sectioned. When distinguishing mycelia of the two species, we took into account the staining grade of mycelia together with their position the hyperparasite was outside of the plant tissues.

Artificial infection. The ability of the hyperparasite to infect E. typhina stromata at various developmental stages was determined in growth chamber. $P$. distans grass was collected from the field
(Giebnia, $52^{\circ} 46.544^{\prime} \mathrm{N}, 18^{\circ} 06.190^{\prime} \mathrm{E}$ ) in late summer of 2013 and stored outside during the winter. This site was chosen because it had the highest incidence of choke in 2013.

For conidial production, we used a strain of the hyperparasite that had been previously isolated from E. typhina stomata collected at the Giebnia site (Table 1). After conidia were incubated for 1.5 months on oatmeal agar (OA) medium, they were collected in sterile distilled water and transferred to sterile tubes. Suspensions were adjusted to three different concentrations $\left(10^{3}, 10^{4}\right.$, and $10^{5}$ spores $\left.\mathrm{ml}^{-1}\right)$ using a Thoma hemocytometer.

Thirty grass individuals were grown in a chamber under constant temperature and humidity $\left(20 / 15^{\circ} \mathrm{C}, 40 \%\right.$ humidity, $16 / 8 \mathrm{~h}$ light/dark photoperiod). Emerging stromata were successively divided into two groups: the first group (unfertilized stromata, U) was treated on the day of appearance; the second (fertilized stromata, F) was treated at $1,2,10$, and 20 days after fertilization. We used a total of 15 unfertilized and 60 fertilized stromata. Fertilized stromata were obtained by rubbing stromata of the opposite mating type on the stroma surface of the plants (Bacon and White 1994). We assumed that fertilization had taken place when the first indications of perithecial development appeared. Every stroma was sprayed with $0.5 \mathrm{ml}$ of the C. epichloë spore suspension at three different concentrations. Control stromata (75) were sprayed with sterile water. To verify spore viability in prepared suspensions, we inoculated PDA and corn meal agar (CMA) media supplemented with chloramphenicol (100 mg/liter) with $0.5 \mathrm{ml}$ of every suspension. Fungal stromata that developed on $P$. distans tillers were examined daily.

Mycoparasitic ability in vitro. Two experiments were designed to evaluate the antagonistic activity of the hyperparasite against E. typhina in vitro. Three strains of E. typhina and three strains of the hyperparasitic fungus, each originating from one of three sites (Table 1), were used in both experiments. E. typhina strains were obtained by placing sterilized $P$. distans leaf segments on PDA medium in Petri dishes. Leaves were collected from the same
A

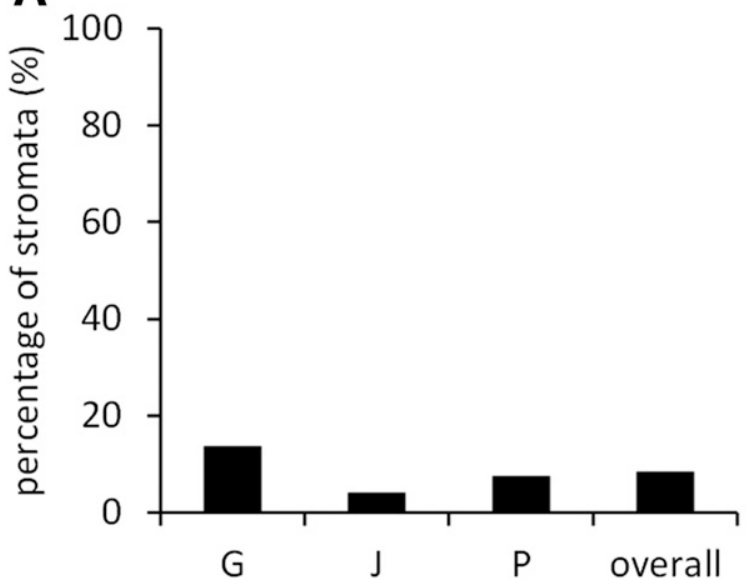

B

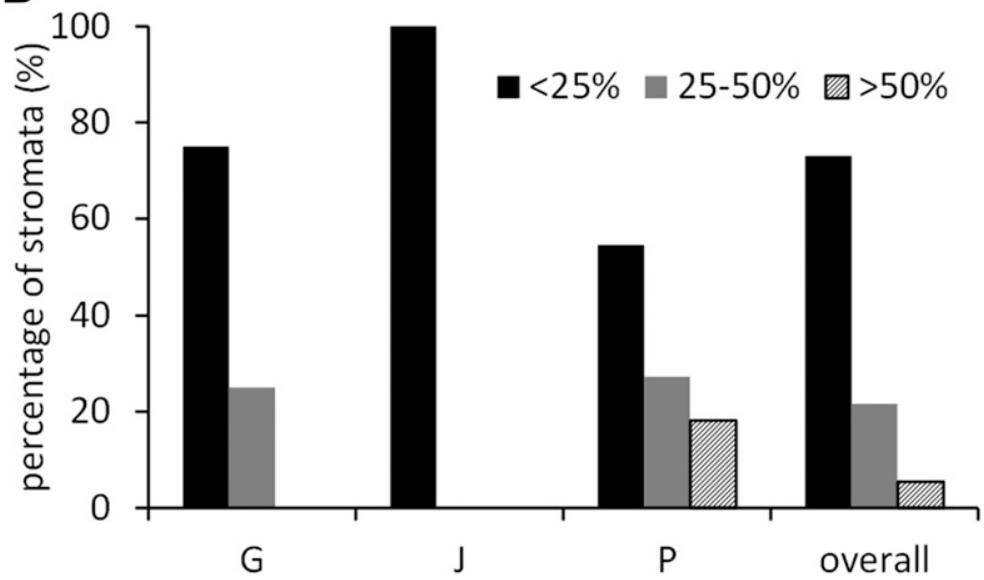

Fig. 3. The presence of Clonostachys epichloë on Epichloë typhina stromata: A, percentage of infected stromata and B, coverage of stromata by C. epichloë. Sites: G, Giebnia; J, Janikowo; and P, Pakość; $n=130$ (at each site).

Table 2. Results of repeated measures ANOVAs. Effects of Clonostachys epichloë strain (CloG, CloJ, CloP), time, and their interactions on mean weekly mycelial growth of three Epichloë typhina strains (EpiG, EpiJ, EpiP).

\begin{tabular}{|c|c|c|c|c|c|c|c|c|c|c|c|c|}
\hline \multirow[b]{2}{*}{ Source of variation } & \multicolumn{4}{|c|}{ EpiG } & \multicolumn{4}{|c|}{ EpiJ } & \multicolumn{4}{|c|}{ EpiP } \\
\hline & $d f^{a}$ & $F^{\mathbf{b}}$ & $\mathbf{M S}^{\mathbf{c}}$ & $P$ & df & $\mathbf{F}$ & MS & $P$ & df & $\mathbf{F}$ & MS & $P$ \\
\hline Clo strain & 3 & 24.32 & 77.46 & $<0.01$ & 3 & 22.38 & 148.76 & $<0.01$ & 3 & 12.91 & 179.01 & $<0.01$ \\
\hline Error & 16 & & 3.19 & & 16 & & 6.65 & & 16 & & 13.86 & \\
\hline Time & 4 & 65.97 & 128.89 & $<0.01$ & 4 & 17.99 & 144.14 & $<0.01$ & 4 & 23.77 & 202.31 & $<0.01$ \\
\hline Clo strain $\times$ time & 12 & 11.31 & 22.09 & $<0.01$ & 12 & 5.29 & 42.38 & $<0.01$ & 12 & 5.33 & 45.38 & $<0.01$ \\
\hline Error & 64 & & 1.95 & & 64 & & 8.01 & & 64 & & 8.51 & \\
\hline
\end{tabular}

\footnotetext{
a Degrees of freedom.

${ }^{b}$ F-statistic.

c Mean squares.
} 
individuals of $P$. distans from which stromata infected with the hyperparasite were previously collected. Morphological and molecular identification confirmed the identity of the obtained strains as E. typhina (Table 1). All available combinations of hyperparasitic fungus and E. typhina strains were tested.

Experiment 1. An antagonism assay was performed on PDA in Petri dishes using a dual-culture method. Two $5 \mathrm{~mm}$ diameter agar plugs, one fully covered with the hyperparasite and one with E. typhina mycelium, were placed at opposite ends of PDA plates (90 mm), $1 \mathrm{~cm}$ from the edge. Dishes inoculated with only E. typhina served as controls. Plates were incubated at $25^{\circ} \mathrm{C}$, and five replicates of both the paired cultures and controls were performed.

Measurements of the growth of dual cultures and controls were performed at weekly intervals starting 1 week after inoculation. The percent growth inhibition (PGI) was calculated using the following formula: PGI $(\%)=(\mathrm{R}-\mathrm{R} 1) / \mathrm{R} \times 100$, where $\mathrm{R}$ represents the distance (measured in $\mathrm{mm}$ ) from the point of inoculation to the
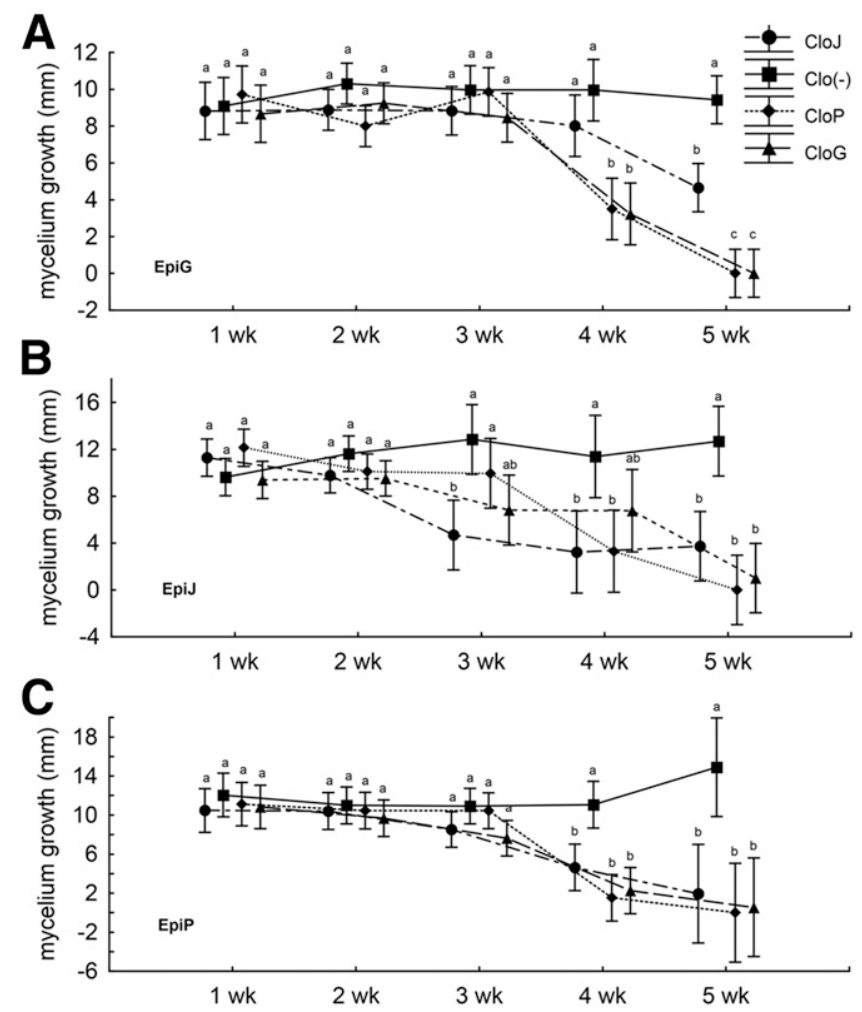

Fig. 4. Growth patterns of Epichloë typhina mycelia in strains EpiG (A), EpiJ (B), and EpiP (C) in the presence of three different strains of Clonostachys epichloë (CloJ, $\mathrm{CloP}, \mathrm{CloG}$ ) and without Clonostachys (Clo-). Values represent means $\pm \mathrm{Cl}$. Different letters indicate significant differences between treatments at each time point (repeated measure analysis was performed using ANOVA and a subsequent Tukey's HSD test; $P<0.05)$. colony margin on the control dishes, and R1 represents the distance of fungal growth from the point of inoculation to the colony margin on the treated dishes in the direction of the antagonist (Korsten et al. 1995). These measurements were also used to estimate mean weekly mycelial growth on dual and control plates.

Additionally, 15 glass slides covered with a thin layer of PDA were inoculated with the hyperparasitic fungus and E. typhina $1.5 \mathrm{~cm}$ apart. Slides were subsequently placed in a Petri dish containing moist filter paper. The sealed Petri dishes served as humid chambers and were incubated at $25^{\circ} \mathrm{C}$ in the dark. The slides were checked daily under an Olympus BX53 microscope to observe typical mycoparasitic hyphal interactions.

Experiment 2. The precolonized plate method was used as described in Evans et al. (2003). An agar plug of $5 \mathrm{~mm}$ diameter, covered with a colony of the hyperparasite, was placed at one edge of a colony of $E$. typhina on a PDA plate $(90 \mathrm{~mm})$. Colonies of E. typhina were 12 weeks old and ranged from 47 to $68 \mathrm{~mm}$ in diameter. After 5 weeks of incubation at $25^{\circ} \mathrm{C}$ in the dark, six to nine samples were removed with a $7 \mathrm{~mm}$ cork borer, starting at the hyperparasite inoculum. The number of samples that were taken varied because of the variable diameters of $E$. typhina colonies on precolonized plates. Samples were plated on OA medium, incubated at $25^{\circ} \mathrm{C}$ in the dark, and observed after 4 weeks to detect the hyperparasite. Percentage of colonization (number of samples with Clonostachys/total number of samples $\times 100$ ) was determined, and comparisons were made between each strain's combinations.

Statistical analysis. A $\chi^{2}$ test was used in intergroup comparisons of the hyperparasite from different sites. We used repeated-measures ANOVA and a subsequent post hoc Tukey's test to determine whether the hyperparasite strain, the time the measurements were taken (after 1, 2, 3, 4, and 5 weeks) and their interactions had a significant effect on the mycelial growth of Epichloë strains. Factorial ANOVA was used for determining the effect of fungal strains on the PGI and percentage of Clonostachys colonization on plates inoculated with Epichlö̈. The assumptions of the tests were validated before the analyses were conducted. The Shapiro-Wilk test was performed to test for normal distributions, while Levene's test was used to confirm the homogeneity of variance in groups. The assumption of sphericity was tested with Mauchly's test. Variables expressed in proportion were arcsine-transformed prior to analysis. Probability values lower than 0.05 were considered to indicate statistically significant differences. All statistical analyses were conducted using Statistica 12 software (StatSoft, Poland).

\section{Results}

Identification and incidence. Dark green sporodochia observed on E. typhina stromata (Fig. 1A) were covered with densely packed, branched conidiophores bearing cylindrical conidia. The colonies on PDA reached up to $22 \mathrm{~mm}$ diameter in 7 days at $25^{\circ} \mathrm{C}$ and produced divergently branched conidiophores with conidia 5.9 to $7.1 \mu \mathrm{m}$ long and 2.1 to $2.8 \mu \mathrm{m}$ wide $(n=100)$ at the broadest part (Fig. 1B), corresponding well to the description of C. epichloë (Speg.) Schroers (sexual morph Bionectria epichlö̈) provided by Schroers (2001) and Kirschner (2006). Obtained sequences and sequences of best

Table 3. Percentage growth inhibition (PGI) of Epichloë typhina growth in dual cultures with Clonostachys epichloë and percentage of E. typhina colonization by C. epichloë, for all E. typhina-C. epichloë strain combinations

\begin{tabular}{lccccc}
\hline & & \multicolumn{3}{c}{ PGI (\%) } \\
\cline { 2 - 5 } Epichlö strain & Clonostachys strain & Week 3 & Week 4 & Week 5 & Percentage of colonization (\%) \\
\hline EpiG & CloG & 8.17 & 23.64 & 38.14 & 68.33 \\
& CloJ & 8.00 & 10.74 & 18.40 & 5.00 \\
EpiJ & CloP & 5.29 & 20.25 & 35.48 & 700 \\
& CloG & 24.25 & 28.67 & 42.58 & 2.22 \\
EpiP & CloJ & 24.22 & 35.98 & 43.59 & 87.70 \\
& CloP & 5.41 & 21.93 & 38.96 & 85.28 \\
& CloG & 16.93 & 32.38 & 46.51 & 75.00 \\
\hline
\end{tabular}


BLAST matches were $99 \%$ for sequences from Janikowo and Pakość and $100 \%$ for those from Giebnia. Phylogenetic analysis of DNA sequences supported the positioning of the fungus within the Clonostachys/Bionectria group (Fig. 2).

The presence of C. epichloë on E. typhina stromata was recorded for samples in the studied localities. The percentage of infected stromata differed significantly between sites $\left(\chi_{2}^{2}=8.92 ; P<0.05\right)$ and ranged from 4.1 to $13.8 \%$ depending on locality (Fig. 3A). Overall, C. epichloë was present on $8.5 \%$ of all collected Epichlö̈ stomata. In over $70 \%$ of the Clonostachys-infected stromata, less than $25 \%$ of the area was covered by Clonostachys mycelia, while the coverage exceeded $50 \%$ in only $5 \%$ of these stromata (Fig. 3B). This situation occurred in all localities, although stroma coverage percentages differed among populations.

Effects on the sexual reproduction of E. typhina. C. epichloë in the structures of Epichloë stromata. C. epichloë were present both on the surface of and within stromata. In semi-thin sections of the material observed under a microscope, no asci of E. typhina were observed within the perithecia of the parts of stromata colonized by C. epichloë whereas uninfected parts of E. typhina had fully developed perithecia with asci (Fig. 1C and D). Results were consistent for all 36 stromata. In addition, a portion of the stroma was destroyed, resulting in only compacted, empty mycelial walls being visible. Some loose mycelia, presumably from the hyperparasite, were present inside the perithecia. Epichloë hyphae were clearly visible between the cells of various plant tissues; even the sclerenchyma and xylem were infected (Fig. 1E). While the presence of E. typhina within plant tissues was clear, we could not exclude the possibility that $C$. epichlö was also present there. The same results were obtained for all prepared sections.

Artificial infection. None of the E. typhina stromata treated with spore suspensions of $C$. epichlö̈ and none of the control stromata, sprayed with water, showed signs of $C$. epichloë mycelia. The spore suspensions contained living spores of C. epichloë, which was confirmed by inoculation of PDA and CMA media.

Mycoparasitic ability in vitro. Experiment 1. All three strains of C. epichlo $\ddot{e}$ inhibited growth of each of the three Epichlo $\ddot{e}$ strains (Table 2), and all Clonostachys strains similarly impacted the mean weekly growth of individual Epichloë strains (Tukey HSD, NS). The only exception was Clonostachys strain CloJ, which restricted the growth of the Epichloë EpiG strain less than the other two Clonostachys strains (Tukey HSD; $P<0.05$ ). Inhibition of Epichlö growth by Clonostachys was first recorded in the third week of the experiment, for the CloJ-EpiJ combination (Fig. 4B). This Clonostachys strain inhibited the growth of two other Epichloë strains only in the fourth (EpiP strain, Fig. 4C) or fifth week (EpiG, Fig. 4A). The remaining Clonostachys strains- $\mathrm{CloG}$ and $\mathrm{CloP}-$ inhibited the growth of Epichloë in the fourth week (CloP affected all three Epichloë strains) and in the fourth (CloG-EpiP, CloG-EpiG) or fifth week (CloG-EpiJ).

The PGI of E. typhina strains by all three C. epichloë strains was calculated. Inhibition increased consistently in all combinations of Epichloë and Clonostachys associations and, in the fifth week, varied from $18.40 \%$ for EpiG-CloJ to $46.50 \%$ for EpiP-CloG associations (Table 3). Analysis of the PGI values showed no differences in

Table 4. Results of ANOVA showing effects of fungal strains on the percentage growth inhibition (PGI) and colonization ability of Clonostachys epichloë (as measured by the precolonized method) toward Epichloë typhina

\begin{tabular}{|c|c|c|c|c|c|c|c|c|}
\hline \multirow[b]{2}{*}{ Source of variation } & \multicolumn{4}{|c|}{ PGI } & \multicolumn{4}{|c|}{ Colonization ability } \\
\hline & $d f^{a}$ & $F^{\mathbf{b}}$ & $\mathbf{M S}^{\mathbf{c}}$ & $P$ & df & $\mathbf{F}$ & MS & $P$ \\
\hline Epi strain & 2 & 5.14 & 0.06 & $<0.01$ & 2 & 0.10 & 0.01 & $\mathrm{NS}^{\mathrm{d}}$ \\
\hline Clo strain & 2 & 2.65 & 0.03 & NS & 2 & 66.53 & 3.16 & $<0.01$ \\
\hline Epi strain $\times$ Clo strain & 4 & 1.58 & 0.02 & NS & 4 & 1.16 & 0.05 & NS \\
\hline Error & 36 & & 0.01 & & 36 & & 0.05 & \\
\hline
\end{tabular}

a Degrees of freedom.

${ }^{\mathrm{b}}$ F-statistic.

${ }^{\mathrm{c}}$ Mean squares.

${ }^{\mathrm{d}}$ Not significant. inhibition between individual Clonostachys strains (Table 4), but two Epichloë strains-EpiJ and EpiP-were more inhibited by Clonostachys (Table 4, Fig. 5A).

Mycelia of C. epichlö̈ and E. typhina occur together on slides with PDA; nonetheless, no typical mycoparasitic hyphal interactions (e.g., hyphal coiling or penetration resulting in the ultimate collapse of the host cells) were observed.

Experiment 2. The percentage of Clonostachys colonization on plates inoculated with Epichlö̈ was determined using the precolonized method. The use of OA medium enabled easy recognition of Clonostachys because of the dark green sporodochia that it forms on this medium. The percentage of colonization ranged from 2.22 to $100 \%$ (Table 3 ). The percentage of colonization by the mycoparasite did not differ between the three Epichlö̈ strains, but differed between the three Clonostachys strains (Table 4); the CloJ strain colonized E. typhina significantly less than the other strains (Fig. 5B) Total colonization of E. typhina, resulting in the complete suppression of growth, was achieved with only one C. epichlö̈ strain, CloP, which overgrew Epichlö̈ strain EpiG. Only one Epichloë strain-EpiP — was more than $70 \%$ colonized by all three Clonostachys strains. Low percentages of colonization were observed when the two remaining strains, EpiG and EpiJ, were inoculated with Clonostachys strain CloJ (Table 3).

\section{Discussion}

Results of our study demonstrate that (1) stromata of E. typhina on $P$. distans are colonized by the hyperparasitic fungus, C. epichloë; (2) C. epichloë invades the stromata and restricts the sexual reproduction of E. typhina; and (3) C. epichlö̈ inhibits the growth of E. typhina mycelia under in vitro conditions. These findings support the parasitic relationship between these two fungal species.

C. epichloë was previously found on dead rachises of ferns (Pteridium aquilinum) and grasses (e.g., Sasa sp.) (Schroers 2001). It was also found on Epichloë stromata in America, Asia (Schroers 2001), and Europe (Kirschner 2006; Steinebrunner et al. 2008a). In both cases, this fungus was described as a mycoparasite, but its incidence, distribution, and effect on developing Epichloë stromata were not investigated. This study is therefore the first that investigates the ecology of Epichlö̈-Clonostachys interaction.

The presence of $C$. epichloe in E. typhina stromata, which was observed at all of the studied localities, results in an abortion of the sexual reproduction of the latter. Ascospore development was completely suppressed by $C$. epichloë, and only empty perithecia without asci and ascospores were observed. C. epichloë can thus restrict the potential number of ascospores and decrease the horizontal spread of E. typhina. In vitro experiments also support these findings, although no typical mycoparasitic hyphal interactions between E. typhina and C. epichlö̈ mycelia were observed. C. epichlö̈ restricted E. typhina growth, with PGI values over $30 \%$ in the fifth week of the experiment. The precolonized plate method also indicated the negative impact of C. epichlö̈ on Epichlö̈. After this
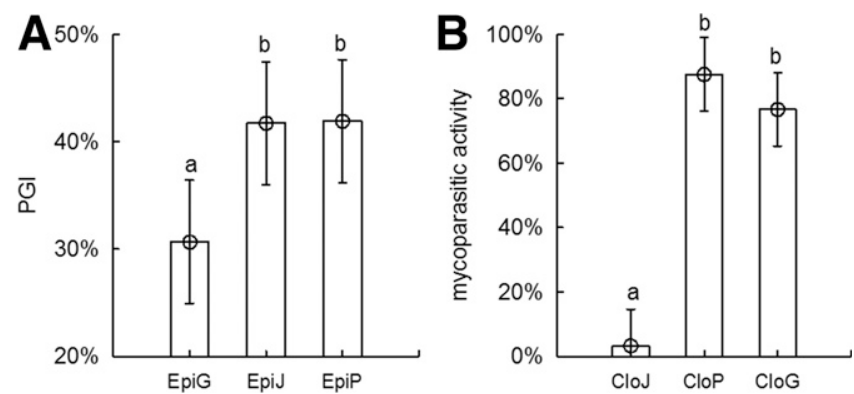

Fig. 5. A, Percentage growth inhibition (PGI) of three Epichloë typhina strains (EpiG, EpiJ, EpiP) in dual cultures with Clonostachys epichloë (due to lack of differences in inhibition ability between Clonostachys strains [Table 4], they were treated as a whole in the figure) and $\mathbf{B}$, colonization ability of $\mathbf{C}$. epichloë (as measured by the precolonized method) toward E. typhina. Values represent means $\pm \mathrm{Cl}$. Means with different letters are significantly different (Tukey's HSD, $P<0.05$ ). 
fungus was transferred to a plate colonized with Epichloë, it quickly spread and covered up to $100 \%$ of the area. In both experiments, the CloJ strain showed a clearly lower effectiveness, e.g., when the precolonized plate method was used, CloJ colonized just $2.22 \%$ of EpiJ and $5 \%$ of EpiG (Table 3). This result suggested that different strains of a particular pathogenic fungal species may respond differently in terms of inhibition of a particular antagonist. C. epichloë inhibited E. typhina from 18.40 to $46.51 \%$ in dual culture, and its ability to colonize E. typhina in the pre-colonized experiments ranged from 2.2 to $100 \%$. These results suggest that C. epichloë strains exhibit broad spectrum antagonistic activity that is important for biocontrol.

The mycoparasitic abilities of C. epichloë on E. typhina enable this fungus to potentially function as a biocontrol agent against choke disease. Prevention and eradication of choke disease is difficult. Chemical fungicides are ineffective (Alderman et al. 2008; Fermaud 1986; Leyronas and Raynal 2008; Pfender and Alderman 2003), and other more effective methods (e.g., burning plant residues) are presently abandoned due to their negative impact on ecosystems. For these reasons, the use of biological agents based on natural enemies of the pathogen may be a promising alternative.

Although Epichloë is rarely infected by hyperparasites in nature, several mycoparasites have been found on its stromata: Dicyma pulvinata (Alderman et al. 2010), Cladosporium epichloës (Heuchert et al. 2005; Ruszkiewicz-Michalska 2010), Ramichloridium epichloës (Arzanlou et al. 2007), Phyllosticta epichloës (van der Aa and Vanev 2002), Alternaria sp. (Mułenko et al. 2008), and Nodulisporium sp. (Steinebrunner et al. 2008a), in addition to C. epichlö̈. However, these reports only note the occurrence of these fungi on stromata. Significant reduction in Epichloë perithecial development as the results of mycoparasitism has only be reported for $D$. pulvinata (Alderman et al. 2010). In the U.S.A., D. pulvinata was recognized as a potential biocontrol agent of leaf spot disease of peanut caused by Cercosporidium personatum (Mitchell and Taber 1986). Further studies on the usefulness of $D$. pulvinata for choke disease prevention have not been conducted.

C. epichlö̈ was present at all studied $P$. distans sites, including two other P. distans sites (M. Lembicz, and K. Górzyńska, unpublished). The incidence of C. epichloë was rather low-it was found in less than $10 \%$ of the collection, which is comparable to the incidence of D. pulvinata on Epichloë stromata in the U.S.A. (Alderman et al. 2010). Moreover, the area covered by mycelia was below $25 \%$ in more than $70 \%$ of all the Clonostachys-infected stromata. These results are not spectacular when we consider the potential application of C. epichloë as a biocontrol agent, but they may be explained in two ways: the incidence of occurrence, and colonization of E. typhina by C. epichloë reflects the natural occurrence under the current environmental conditions of the study; also, it represented only one year. Environmental factors influence spore germination, infection, and the destructive activity of mycoparasites (e.g., Partridge et al. 2006). During our study, the weather conditions were unfavorable for both fungi (very high temperature and low humidity).

The studies of the hyperparasite- $E$. typhina interaction involving the artificial infection were not successful. We had hoped to demonstrate the most appropriate time to inoculate with a biocontrol agent, during initial stromatal development or after fertilization of the E. epichloë. The failure of Clonostachys inocula to form hyperparasitic colonies on E. epichloë in our experiments is difficult to explain. Temperature and humidity conditions as well as concentrations of conidial suspensions were confirmed on control plates with Clonostachys spores. A possible explanation is that volatile organic compounds (VOCs) that are emitted by Epichlö stromata prevented conidium germination. These compounds attract Botanophila flies, a vector of spermatia that enables Epichlö̈ to cross-fertilize and sexually reproduce (Steinebrunner et al. 2008c). The VOCs also exhibit antimicrobial properties toward the fungal hyperparasites, including Clonostachys (Steinebrunner et al. 2008a). The presence of VOCs was also investigated in E. typhina on $P$. distans grass, and methyl 2,4,8-trimethylundecanoate (MTE) was the main compound involved in this association (Steinebrunner et al. 2008b). MTE was not produced under in vitro conditions and it has been suggested that precursory substances of plant origin are needed for its production (Steinebrunner et al. 2008a). These findings may explain the ease with which C. epichloë spores germinate on PDA plates and the difficulties with its germination on stomata on grass culms. Although the antifungal activity of MTE has not been proved (Steinebrunner et al. 2008a), its high production in $P$. distans-associated stromata and lack of in vitro production are consistent with our results. Further studies are needed to test the factors mentioned above.

In summary, C. epichlo $\ddot{e}$ is a significant hyperparasite of E. typhina, an important parasite of many grass species, including P. distans. C. epichloë is potentially a viable candidate as a biocontrol agent, but additional studies are needed to determine the optimum conditions for infection.

\section{Literature Cited}

Alderman, S. C., Rao, S., and Martin, R. C. 2010. First report of Dicyma pulvinata on Epichloë typhina and its potential for E. typhina control. Plant Health Prog. doi.org/10.1094/PHP-2010-0216-01-RS

Alderman, S. C., Rao, S., Spinney, R. L., Boren, P. K., and Cacka, J. F. 2008. Summary of choke control studies. Pages 19-25 in: Seed Production Research at Oregon State University. W. C. Young III, ed. Ohio State University Extension Service, Columbus, OH

Arzanlou, M., Groenewald, J. Z., Gams, W., Braun, U., Shinh, D., and Crous, P. W. 2007. Phylogenetic and morphotaxonomic revision of Ramichloridium and allied genera. Stud. Mycol. 58:57-93.

Bacon, C. W., and White, J. F., Jr. 1994. Biotechnology of endophytic fungi of grasses. CRC Press, Boca Raton, FL.

Brem, D., and Leuchtmann, A. 2001. Epichloë grass endophytes increase herbivore resistance in woodland grass Brachypotium sylvaticum. Oecologia 126:522-530.

Bultman, T. L., White, J. F., Jr., Bowdish, T. I., and Welch, A. M. 1998. A new kind of mutualism between fungi and insects. Mycol. Res. 102:235-238.

Cagaš, B., and Macháč, R. 2012. Effect of some factors on the incidence of choke (Epichloë typhina) in grass seed stands in Czech Republic. Plant Prot. Sci. 48: $10-16$

Chung, K. R., and Schardl, C. L. 1997. Sexual cycle and horizontal transmission of the grass symbiont, Epichloë typhina. Mycol. Res. 101:295-301.

Conover, M. R. 2003. Impact of the consumption of endophyte-infected perennial ryegrass by meadow voles. Agric. Ecosyst. Environ. 97:199-203.

Czarnoleski, M., Olejniczak, P., Górzyńska, K., Kozłowski, J., and Lembicz, M. 2013. Altered allocation to roots and shoots in the endophyte-infected seedlings of Puccinellia distans (Poaceae). Plant Biol. 15:264-273.

Czarnoleski, M., Pawlik, K., Olejniczak, P., Kozłowski, J., and Lembicz, M. 2012. An endophytic fungus reduces herbivory in its recently colonised grass host: a food-choice experiment on common voles, weeping alkaligrass and Epichlö̈ typhina. Plant Ecol. 213:1049-1053.

Elad, Y. 2000. Trichoderma harzianum T39 preparation for biocontrol of plant diseases - control of Botrytis cinerea, Sclerotinia sclerotiorum and Cladosporium fulvum. Biocontrol Sci. Technol. 10:499-507.

Evans, H. C., Holmes, K. A., and Thomas, S. E. 2003. Endophytes and mycoparasites associated with an indigenous forest tree, Theobroma gileri, in Ecuador and a preliminary assessment of their potential as biocontrol agents of cocoa diseases. Mycol. Prog. 2:149-160.

Fermaud, M. 1986. Epidémiologie de la quenouille du dactyle porte-graine due à Epichlö̈ typhina (Pers. ex Fr.) Tulasne. Mémoire de fin d'étude pour l'obtention du DAA. Ecole Nationale Supérieure d'Agronomie, Montpellier, France.

Gardes, M., and Bruns, T. D. 1993. ITS primers with enhanced specificity of basidiomycetes: application to the identification of mycorrhizae and rusts. Mol. Ecol. 2:113-118.

Gordon, T. C., and Pfender, W. F. 2012. Effects of the mycoparasite Sphaerellopsis filum on overwintering survival of stem rust in perennial ryegrass. Plant Dis. 96:1471-1481.

Górzyńska, K., Lembicz, M., Olszanowski, Z., and Leuchtmann, A. 2011. Botanophila-Epichloë interaction in a wild grass, Puccinellia distans, lacks dependence on the fly vector. Ann. Entomol. Soc. Am. 104:841-846.

Górzyńska, K., Ryszka, P., Anielska, T., Turnau, K., and Lembicz, M. 2017. Effect of Epichloë typhina fungal endophyte on the diversity and incidence of other fungi in Puccinellia distans wild grass seeds. Flora 228:60-64.

Guerre, P. 2016. Lolitrem B and indole diterpene alkaloids produced by endophytic fungi of the genus Epichlö̈ and their toxic effects in livestock. Toxins (Basel) 8:47.

Guindon, S., Dufayard, J. F., Lefort, V., Anisimova, M., Hordijk, W., and Gascuel, O. 2010. New algorithms and methods to estimate maximum-likelihood phylogenies: assessing the performance of PhyML 3.0. Syst. Biol. 59:307-321.

Gundel, P. E., Maseda, P. H., Vila-Aiub, M. M., Ghersa, C. M., and BenechArnold, R. 2006. Effects of Neotyphodium fungi on Lolium multiflorum seed germination in relation to water availability. Ann. Bot. 97:571-577.

Harveson, R. M., Kimbrough, J. W., and Hopkins, D. L. 2002. Novel use of a pyrenomycetous mycoparasite for management of Fusarium wilt of watermelon. Plant Dis. 86:1025-1030. 
Hesse, U., Schöberlein, W., Wittenmayer, L., Forster, K., Warnstorff, K., Diepenbrock, W., and Merbach, W. 2005. Influence of water supply and endophyte infection (Neotyphodium spp.) on vegetative and reproductive growth of two Lolium perenne L. genotypes. Eur. J. Agron. 22:45-54.

Heuchert, B., Braun, W., and Schubert, K. 2005. Morphotaxonomicrevision of fungicolous Cladosporium species (hyphomycetes). Schlechtendalia (Halle) 13:1-78.

Hoveland, C. S. 1993. Importance and economic significance of Acremonium endophytes on performance of animals and grass plant. Agric. Ecosyst. Environ. 44:3-12.

Hughes, W. E., and Hallidays, S. 1980. Puccinellia Parl. Pages 167-169 in: Flora europaea 5. Alismataceae to Orchidaceae (Monocotyledones). T. G. Tutin, V. H. Heywood, N. A. Burges, D. M. Moore, O. H. Valentine, S. M. Walter, and D. A. Webb, eds. Cambridge University Press, U.K.

Jeffries, P. 1995. Biology and ecology of mycoparasitism. Can. J. Plant Pathol. 73: 1284-1290.

Jeffries, P., and Young, T. W. K. 1994. Interfungal Parasitic Relationship. CAB International, Wallingford, U.K.

Katoh, K., Misawa, K., Kuma, K., and Miyata, T. 2002. MAFFT: a novel method for rapid multiple sequence alignment based on fast Fourier transform. Nucleic Acids Res. 30:3059-3066.

Katoh, K., and Standley, D. M. 2013. MAFFT multiple sequence alignment software version 7: improvements in performance and usability. Mol. Biol. Evol. 30:772-780.

Kirschner, R. 2006. New records of Clonostachys epichlö̈, a mycoparasitic fungus on the grassparasitic ascomycete Epichloë typhina for Europe. Feddes Repert. 117:307-311.

Korsten, L., De Jager, E. S., De Villers, E. E., Lourens, A., Kotze, J. M., and Wehner, F. C. 1995. Evaluation of bacterial epiphytes isolated from avocado leaf and fruit surfaces for biocontrol of avocado postharvest diseases. Plant Dis. 79:1149-1156.

Lembicz, M. 1996. Modification of the life cycle and reproductivity of Puccinellia distans (Poaceae) under the effect of parasitic fungus Epichloë typhina. Fragm. Flor. Geobot. 41:591-592.

Lembicz, M., Górzyńska, K., and Leuchtmann, A. 2010. Choke disease, caused by Epichloë bromicola, in the grass Agropyron repens in Poland. Plant Dis. 94: 1372.

Lembicz, M., Górzyńska, K., Olejniczak, P., and Leuchtmann, A. 2011. Geographical distribution and effects of choke disease caused by Epichlö̈ typhina in populations of the grass Puccinellia distans in Poland. Sydowia 63:35-48.

Lembicz, M., Górzyńska, K., Olszanowski, Z., Michelsen, V., and Leuchtmann, A. 2013. The occurrence and preference of Botanophila flies (Diptera: Anthomyiidae) for particular species of Epichloë fungi infecting wild grasses. Eur. J. Entomol. 110:129-134.

Lembicz, M., and Olejniczak, P. 2009. The fungus Epichloë typhina in populations of halophyte Puccinellia distans: salinity as a possible inhibitor of infection. Acta Soc. Bot. Pol. 78:81-86.

Leuchtmann, A., Bacon, C. W., Schardl, C. L., White, J. F., and Tadych, M. 2014. Nomenclatural realignment of Neotyphodium species with genus Epichloë. Mycologia 106:202-215

Leyronas, C., and Raynal, G. 2008. Role of fungal ascospores in infection of orchardgrass (Dactylis glomerata) by Epichloë typhina agent of choke disease. J. Plant Pathol. 90:15-21.

Li, G. Q., Huang, H. C., Acharya, S. N., and Erickson, R. S. 2004. Biological control of blossom blight of alfalfa caused by Botrytis cinerea under environmentally controlled and field conditions. Plant Dis. 88:1246-1251.

Malinowski, D. P., Alloush, G. A., and Belesky, D. P. 2000. Leaf endophyte Neotyphodium coenophialum modifies mineral uptake in tall fescue. Plant Soil 227:115-126.

Meister, B., Krauss, J., Härri, S. A., Schneider, M. V., and Müller, C. B. 2006. Fungal endosymbionts affects aphid population size by reduction of adult life span and fecundity. Basic Appl. Ecol. 7:244-252.
Mitchell, J. K., and Taber, R. A. 1986. Factors affecting the biological control of Cercosporidium leaf spot of peanuts by Dicyma pulvinata. Phytopathology 76: 990-994.

Mułenko, W., Majewski, T., and Ruszkiewicz-Michalska, M. 2008. A preliminary checklist of micromycetes in Poland. Szafer Institute of Botany, Polish Academy of Sciences, Krakow, Poland.

Novas, M. V., Gentile, A., and Cabral, D. 2003. Comparative study of growth parameters on diaspores and seedlings between populations of Bromus setifolius from Patagonia, differing in Neotyphodium endophyte infection. Flora 198:421-426

Olejniczak, P., and Lembicz, M. 2007. Age-specific response of the grass Puccinellia distans to the presence of a fungal endophyte. Oecologia 152: 485-494.

Partridge, D. E., Sutton, T. B., and Jordan, D. L. 2006. Effect of environmental factors and pesticides on mycoparasitism of Sclerotinia minor by Coniothyrium minitans. Plant Dis. 90:1407-1412.

Pfender, W. F., and Alderman, S. C. 2003. Evaluation of postharvest burning and fungicides to reduce the polyetic rate of increase of choke disease in orchardgrass seed production. Plant Dis. 87:375-379.

Pfender, W. F., and Alderman, S. C. 2006. Regional development of orchardgrass choke and estimation of seed yield loss. Plant Dis. 90:240-244.

Płachno, B. J., and Swiatek, P. 2009. Functional anatomy of the ovule in Genlised with remarks on ovule evolution in Lentibulariaceae. Protoplasma 236:39-48.

Płachno, B. J., and Świątek, P. 2010. Unusual embryo structure in viviparous Utricularia nelumbifolia with remarks on embryo evolution in genus Utricularia. Protoplasma 239:69-80.

Raynal, G. 1991. Libération des ascospores d'Epichloe typhina, agent de la quenouille du dactyle. Conséquences pour l'épidémiologie et la lutte. Fourrages (Versailles) 127:345-358

Ronquist, F., and Huelsenbeck, J. P. 2003. MRBAYES 3: Bayesian phylogenetic inference under mixed models. Bioinformatics 19:1572-1574

Ruszkiewicz-Michalska, M. 2010. Cladosporium epichloes, a rare European fungus, with notes on other fungicolous species. Pol. Bot. J. 55:359-371.

Schardl, C. L. 1996. Epichloë species: fungal symbionts of grasses. Annu. Rev Phytopathol. 34:109-130.

Schardl, C. L., Grossman, R. B., Nagabhyru, P., Faulkner, J. R., and Mallik, U. P. 2007. Loline alkaloids: currencies of mutualism. Phytochemistry 68:980-996.

Schroers, H. J. 2001. A monograph of Bionectria (Ascomycota, Hypocreales, Bionectriaceae) and its Clonostachys anamorphs. Stud. Mycol. 46:1-214.

Steinebrunner, F., Schiestl, F. P., and Leuchtmann, A. 2008a. Ecological role of volatiles produced by Epichloë: differences in antifungal toxicity. FEMS Microbiol. Ecol. 64:307-316.

Steinebrunner, F., Schiestl, F. P., and Leuchtmann, A. 2008b. Variation of insect attracting odor in endophytic Epichloë fungi: phylogenetic constrains versus host influence. J. Chem. Ecol. 34:772-782

Steinebrunner, F., Twele, R., Francke, W., Leuchtmann, A., and Schiestl, F. P. 2008 c. Role of odour compounds in the attraction of gamete vectors in endophytic Epichloë fungi. New Phytol. 178:401-411.

Swofford, D. L. 1998. PAUP*. Phylogenetic Analysis Using Parsimony (*and Other Methods), Version 4. Sinauer Associates, Sunderland, MA

van der Aa, H. A., and Vanev, S. 2002. A revision of the species described in Phyllosticta. Centraalbureau voor Schimmelcultures, Utrecht, Netherlands.

Western, J. H., and Cavett, J. J. 1959. The choke disease of cocksfoot (Dactylis glomerata) caused by Epichloë typhina (Fr). Tul. Trans Br. Mycol. Soc. 42: 298-307.

White, T. J., Bruns, T., Lee, S., and Taylor, J. 1990. Amplification and direct sequencing of fungal ribosomal RNA genes for phylogenetics. Pages 315-322 in: PCR Protocols: A Guide to Methods and Applications. M. A. Innis, D. H. Gelfand, J. J. Shinsky, and T. J. White, eds. Academic Press, San Diego.

Żurek, M., Wiewióra, B., Żurek, G., and Prończuk, M. 2012. Occurrence of endophyte fungi on grasses in Poland - Review. Fungal Ecol. 5:353-356. 